\title{
Double Non Coronary Aortic Sinuses: An Autopsy Case Finding Showing the Arterial Variation
}

\author{
Senos Aórticos Dobles, no Coronarios: Un caso de Autopsia que Demuestra la Variación Arterial
}

Y.P. Raghavendra Babu*; B.V. Murlimanju**; Kausalya Kumari Sahu***; Kanika Gupta***** \& Vasudha V. Saralaya**

RAGHAVENDRA BABU, Y. P.; MURLIMANJU, B. V.; KUMARI SAHU, K.; GUPTA, K. \& SARALAYA, V. V. Double non coronary aortic sinuses: An autopsy case finding showing the arterial variation. Int. J. Morphol., 34(3):1148-1150, 2016.

SUMMARY: We report a case of variant origin of the right coronary artery from the left posterior aortic sinus. This was observed routinely during a medico legal autopsy of a 58 year old male who died in a road traffic accident. Initially it was believed that the right coronary artery was absent since there was no obvious right coronary artery ostium from the anterior aortic sinus. However it was found later that the right coronary ostium was present just beside the left coronary ostium in the left posterior aortic sinus and the right coronary artery was arising from the left posterior aortic sinus. The right coronary artery had an intramural course between the aorta and pulmonary trunk, which is considered as very dangerous and life threatening. We believe that the present case report will be enlightening to the cardiologist and cardiothoracic surgeon. It is also true that the conduction of medico legal autopsies of coronary arteries is important for the medico legal resolution.

KEY WORDS: Aortic Sinus; Coronary Artery Ostium; Right Coronary Artery; Left Coronary Artery.

\section{INTRODUCTION}

The human heart gets the oxygen and nutrition from the coronary arteries which are two in number. They are considered as the vasa vasora, which branch from the ascending aorta. The part of aorta which provides origin to the coronary artery is termed as the aortic sinus. In the normal anatomy, the right coronary artery (RCA) branches from the anterior aortic sinus and the left coronary artery (LCA) are confined to the left posterior aortic sinus (Turner \& Navaratnam, 1996). The right posterior aortic sinus is not giving origin to the coronary artery and is known as noncoronary sinus. The anterior aortic sinus and left posterior aortic sinus are clinically termed as right coronary sinus and left coronary sinus respectively since they provide origin to the RCA and LCA. However there are few cases reported (Andreou et al., 2009) in which the coronary artery was arising from the other coronary sinus and not from its own. The variant origin of the coronary artery has a prevalence rate of $1.1 \%$, it is $0.2 \%$ for the LCA and $0.9 \%$ for RCA respectively (Angelini, 2007). The variant origin of the coronary artery may cause sudden death, usually presented in young individuals who do lots of exertion. Otherwise this anomaly can cause ischemic chest pain on exertion which can be considered as the ischemic heart disease. The other symptoms include palpitations, arrhythmias, dyspnea and syncope (Angelini). In the present case, we report a variant origin of the RCA from the left posterior aortic sinus. The clinical implications of this arterial variation are discussed. The morphological knowledge of the variant origin of the coronary artery and its associated complications is very important to the interventional cardiologist and the cardiothoracic surgeon.

\section{CASE REPORT}

A male aged 58 years with an alleged history of road traffic accident was brought to the hospital. The patient was dead before reaching the hospital due to the severe head injury. During the medico-legal autopsy procedure, the heart was examined along with the other viscera. The internal examination of ascending aorta revealed an anomalous origin of the RCA from the left posterior aortic sinus (Fig. 1). Initially it was thought that the RCA was absent since there was no obvious coronary ostium from the anterior aortic sinus. In other words, it was observed that the anterior aortic sinus was non coronary. However it was found later that the

\footnotetext{
* Department of Forensic Medicine and Toxicology, Koppal Institute of Medical Sciences, Koppal, India.

** Department of Anatomy, Kasturba Medical College, Manipal University, Mangalore, India.

*** Department of Pathology, Kasturba Medical College,Manipal University, Mangalore, India.

***** Undergraduate Trainee, Kasturba Medical College, Manipal University, Mangalore, India.
} 
right coronary ostium was present just beside the left coronary ostium (Fig. 1) in the left posterior aortic sinus. The distance between both the ostia was $3 \mathrm{~mm}$ and both the ostia were located at the same level. The sinutubular ridge was arched to accommodate both the left and right coronary ostia. The RCA also had intramural course in between the pulmonary trunk and aorta. There was no other variant anatomy observed in any other arteries of the heart. The heart was fixed in formalin solution and was sent for histopathological examination.

During the histopathological examination, both the coronary arteries were observed. Both the coronary ostia were arising from the same point. Sections from the aorta showed grade III atherosclerotic change and the left anterior descending artery was showing grade $\mathrm{V}$ atherosclerotic change with $95 \%$ obstruction of lumen. No other anatomical and pathological abnormalities were observed. There were no pathological changes observed in the RCA.

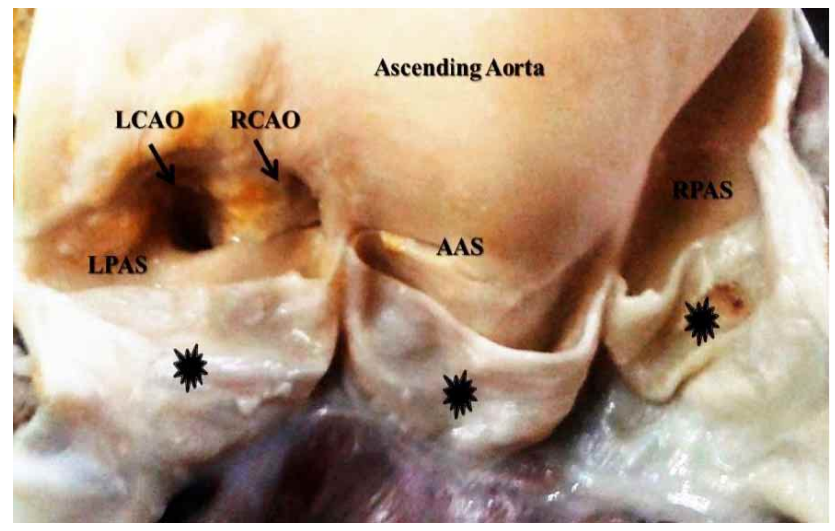

Fig. 1 Interior of the ascending aorta showing the variation, origin of the right coronary artery from the LPAS (AAS-anterior aortic sinus; RPAS-right posterior aortic sinus; LPAS-left posterior aortic sinus; RCAO-right coronary artery ostium; LCAO-left coronary artery ostium; *-aortic valve leaflets).

\section{DISCUSSION}

The variations of the coronary artery are confusing and are the neglected ones in the cardiology literature (Angelini et al., 2002). The variant coronary artery origins were anatomically studied in the initial years (Roberts, 1986). Their incidence was eventually addressed in autopsy hearts and coronary angiograms (Angelini et al., 1999). In the American population, it was reported that the incidence of variant origin of the RCA from the left posterior aortic sinus was $0.92 \%$ and the variant origin of the LCA from the anterior aortic sinus was $0.15 \%$ (Angelini et al.,1999). It has been reported that any congenital variation of the coronary artery with an incidence rate of $>1 \%$, should be considered as abnormal (Becker \& Anderson, 1981). Arterial variations are common in both the medium and large sized vessels like aorta (Chai et al., 2013). The coronary artery variations are a diverse group of anomalies having variable etiologies and consequences (Angelini). The subject of variant coronary anatomy is undergoing profound evolutionary changes in relation to its morphogenesis, clinical implication, investigation and management (Angelini). Coronary arterial variations can lead to sudden death if they are found along with other cardiac malformations and sometimes they are observed solitary too (Türkmen et al., 2007). Turner \& Navaratnam observed a case of RCA which was arising from the right posterior aortic sinus as in the present case. It has been reported that the anomalous origin of the coronary artery from the opposite coronary sinus can be one of the reason for the sudden death in the young. It has been advised that there should be a special solid protocol for the clinical screening for the young athletes and people with extreme exertion in their day to day life. The intravascular ultrasound is the best method to investigate the complications of the variant origin of the coronary artery from the opposite coronary sinus (Angelini).

In a study of 25-year review of autopsies in military recruits, it was observed that $33 \%$ of sudden cardiac deaths were related to the variant origin of the LCA from the anterior aortic sinus (Eckart et al., 2004). It is reported that, $59 \%$ of patients with LCA originating from the anterior aortic sinus will expire in the younger age, usually after a severe exercise (Angelini et al., 2002). It is interesting to note that the patient in the present case died due to the automobile crash and not due to the cardiac pathology. The present case had the anomalous origin of the RCA and there exists no data on the sudden cardiac deaths from this type of variation. However it has been reported that the variation of RCA with intramural course in between the aorta and pulmonary trunk, as observed in the present case is associated with a poor prognosis (Grollman et al., 1992). This type is called as 'interarterial type' and the RCA will be under a scissors kind of mechanism, created by the close proximity of the pulmonary trunk and the aorta, after a workout (Grollman et al.). The sudden death is not the only complication of the variant coronary ostium; the list includes ischemic chest pain, giddiness, dyspnea, palpitations and syncope (Angelini et al., 1999). It has been reported that the sudden death is commonly observed in the young individuals, the other complications are usually seen in the elderly patients (Liberthson, 1989).

Angelini suggested that the patients with clinical symptoms because of variant origin of the coronary artery from the opposite coronary sinus may go for medical and surgical interventions like coronary angioplasty and stent deployment. 
It has been reported that conduction of autopsies of coronary arteries is important for the medicolegal resolution (Türkmen et al.). The demonstration of coronary arterial variations in the medicolegal autopsies is essential to the understanding of sudden death cases related to this type of variations and for the development of new management. In the present study, the histopathological examination of the RCA was found normal. This finding supports the opinion of Türkmen et al., who reported that there is no increased risk for the development of atheromatic plaques in the anomalous coronary arteries.
It has been reported that the clinical implications of the publication of anatomical variations is high and may help in managing the difficulty in the diagnosis and it will prevent the risk of iatrogenic injuries (Bergman, 2011; Duparc, 2011). We believe that the present case report will be enlightening to the cardiologist and cardiothoracic surgeon. The coronary angiography, which will be done prior to the cardiac surgery, is crucial in identifying this type of anatomical variation. This would prevent the misinterpretation and subsequent complications.

RAGHAVENDRA BABU, Y. P.; MURLIMANJU, B. V.; KUMARI SAHU, K.; GUPTA, K. \& SARALAYA, V. V. Senos aórticos dobles, no coronarios: Un caso de autopsia que demuestra la variación arterial. Int. J. Morphol., 34(3):1148-1150, 2016.

RESUMEN: Se presenta un caso de variación de origen de la arteria coronaria derecha desde el seno aórtico posterior izquierdo. Esto se observó de forma rutinaria durante una autopsia médico-legal de un hombre de 58 años que murió en un accidente de tránsito. Inicialmente se creía que la arteria coronaria derecha estaba ausente ya que no había un ostium observable desde el seno aórtico anterior. Sin embargo, se descubrió más tarde que el ostium de la arteria coronaria derecha estaba presente justo al lado del ostium de la arteria coronaria izquierda en el seno aórtico posterior izquierdo y la arteria coronaria derecha se originaba del seno aórtico posterior izquierdo. La arteria coronaria derecha presentó un recorrido intramural entre la aorta y el tronco pulmonar, que se considera como muy peligroso y potencialmente mortal. Creemos que el presente trabajo será esclarecedor para el cardiólogo y el cirujano cardiotorácico. También consideramos que el conocimiento de la anatomía de las arterias coronarias es importante durante el desarrollo de la autopsia médico-legal para lograr alcanzar una correcta resolución del proceso medicolegal.

PALABRAS CLAVE: Seno aórtico; Ostium de la Arteria Coronaria; Arteria coronaria derecha; Arteria coronaria izquierda.

\section{REFERENCES}

Andreou, A. Y.; Ioannides, M. A.; Avraamides, P. C. \& Georgiou, G. M. Aberrant right coronary artery origin from the left aortic sinus with interarterial course manifesting acute myocardial infarction. Exp. Clin. Cardiol., 14(4):50-2, 2009.

Angelini, P. Coronary artery anomalies: an entity in search of an identity. Circulation, 115(10):1296-305, 2007.

Angelini, P.; Velasco, J. A. \& Flamm, S. Coronary anomalies: incidence, pathophysiology, and clinical relevance. Circulation, 105(20):244954, 2002.

Angelini, P.; Villason, S.; Chan Jr., A. V. \& Diez, J. G. Normal and Anomalous Coronary Arteries in Humans. In: Angelini, P. (Ed.). Coronary Artery Anomalies: A Comprehensive Approach. Philadelphia, Lippincott Williams \& Wilkins, 1999. pp.27-150.

Becker, A. E. \& Anderson, R. H. Coronary Artery Anomalies. In: Becker, A. E. \& Anderson, R. H. (Eds.). Pathology of Congenital Heart Disease. London, Butterworths, 1981. pp. 369-78.

Bergman, R. A. Thoughts on human variations. Clin. Anat., 24(8):938-40, 2011.

Chai, O. H.; Han, E. H.; Kim, H. T. \& Song, C. H. Right-sided aortic arch with the retroesophageal left subclavian artery as the fourth branch. Anat. Cell. Biol., 46(2):167-70, 2013.

Duparc, F. Reply to "Thoughts on human variations". Clin. Anat., 24(8):944, 2011.

Eckart, R. E.; Scoville, S. L.; Campbell, C. L.; Shry, E. A.; Stajduhar, K. C.; Potter, R. N.; Pearse, L. A. \& Virmani, R. Sudden death in young adults: a 25-year review of autopsies in military recruits. Ann. Intern. Med., 141(11):829-34, 2004

Grollman, J. H. Jr.; Mao, S. S. \& Weinstein, S. R. Arteriographic demonstration of both kinking at the origin and compression between the great vessels of an anomalous right coronary artery arising in common with a left coronary artery from above the left sinus of Valsalva. Cathet. Cardiovasc. Diagn., 25(1):46-51, 1992.

Liberthson, R. R. Nonatherosclerotic Coronary Artery Disease. In: Eagle, K. A.; Haber, E.; DeSanctis, R. W. \& Austen, W. G. (Eds.). The Practice of Cardiology. Boston, Little Brown and Company, 1989. pp.614-51.

Roberts, W. C. Major anomalies of coronary arterial origin seen in adulthood. Am. Heart. J., 111(5):941-63, 1986.

Turner, K. \& Navaratnam, V. The positions of coronary arterial ostia. Clin. Anat. 9(6):376-80, 1996

Türkmen, N.; Eren, B.; Fedakar, R. \& Senel, B. Sudden death due to single coronary artery. Singapore Med. J., 48(6):573-5, 2007.

\section{Correspondence to: \\ Associate Professor \\ BV Murlimanju, MD \\ Department of Anatomy \\ Kasturba Medical College \\ Manipal University \\ Mangalore -575004 \\ INDIA}

E-mail: flutemist@gmail.com

Received: 05-09-2015

Accepted: 04-07-2016 